\title{
Oral Health Literacy Among Carers of Special Needs Children in Kuala Terengganu, Malaysia
}

\author{
Fabillah NSA, Mustapa N, Rohani MM, Esa R* \\ Faculty of Dentistry, University of Malaya, Kuala Lumpur
}

\begin{abstract}
Oral health literacy $(\mathrm{OHL})$ is important in empowering people to improve their general and oral health. Carers' OHL may be associated with their ability to deliver good oral healthcare to their children. The aim of this pilot study was to assess the OHL among carers of special needs children. This is a descriptive cross-sectional study of carers in four Community-Based Rehabilitation Centre. Data were collected through a structured face-to-face interview of 40 carers. Oral Health Literacy Malay Version (OHLI-M) was measured using text passages and prompts with a total of 57 items. These items were used to assess comprehension and numerical ability of carers based on domains namely, accessing dental care, understand appointment and following medication instructions. The results showed that majority of the participants had 'marginal' and 'adequate' OHL level of $32.5 \%$ and $52.5 \%$, respectively. Only four (10\%) participants had 'inadequate' OHL level. The 'reading comprehension' and 'numeracy' sections' mean scores were $37.54(95 \% \mathrm{Cl} 35.7-39.4)$ and 38.17 (95\% Cl 34.8-41.6). The total OHL mean score was 75.7 (95\% Cl 71.2-80.2). In conclusion, majority of the carers of special needs children in this sample had moderate OHL. Such information is important to develop more appropriate intervention programmes for carers to match their OHL.
\end{abstract}

Keywords: Comprehension and numeracy, oral health literacy, special needs children

\section{INTRODUCTION}

'Health literacy' refers to the ability to perform basic reading and numerical tasks necessary to navigate the health care environment and act on health care information (1). In addition, the American Dental Association (ADA) defines oral health literacy $(\mathrm{OHL})$ as "the degree to which individuals have the capacity to obtain, process and understand basic health information and services needed to make appropriate oral health decisions" (2). Health literacy also plays a role in empowering people to improve their health by changing their personal lifestyles and living conditions.

Recently, awareness on the importance of $\mathrm{OHL}$ in dentistry has grown and efforts have been directed at adapting the concept of health literacy to dental practice and research (3). It is a new area in research globally and limited study has been reported locally. A current systematic review by Berkman and co-workers reported several studies which found significant associations between low health literacy and poor health outcomes (4). 
Additionally, individuals with low health literacy skills often have poorer health knowledge and health status, unhealthy behaviours, less utilization of preventive services, higher rates of hospitalizations, increased health care costs, and ultimately poorer health outcomes compared to those with higher literacy levels (5-7). Several studies had also shown that $\mathrm{OHL}$ was associated with adults' oral health status (8-9) as well as their children's oral health (10-12). Conversely, several studies reported that there was no association between $\mathrm{OHL}$ and dental utilization (13-14). Only one study had explored the $\mathrm{OHL}$ among carers of adults with disabilities in Australia (15).

Currently, four $\mathrm{OHL}$ instruments have been reported (16). The Rapid Estimate of Adult Literacy in Dentistry (REALD-30) and REALD-99 were used for word recognition. The third instrument, the Test of Functional Health Literacy for adults (TOFHLA) was later modified to Test of Functional Health Literacy in Dentistry (TOFHLiD). It consisted of a 68item reading comprehension section and a 12-item numeracy section. The fourth instrument namely the Oral Health Literacy Instrument (OHLI) was modelled from TOFHLA. The Malay version of the Oral Health Literacy Instrument (OHLI-M) was cross culturally adapted and its psychometric properties been tested on a sample of adult (17).

Health literacy instruments have been commonly used among the general population. In this study, the special needs carers were selected as our target group. Children with special health care needs (CSHCN) are those children who have "physical, developmental, mental, sensory, behavioural, cognitive or emotional impairment or limiting condition that require medical management, health care intervention, and/ or use of specialised services or programs" (18). Additionally, those CSHCN may also require continuous care and a multitude of special services involving health facilities, education, transportation and social services, compared to those services required by children without special health care needs (19). These children commonly had problems receiving oral health care due to barriers in accessing the dental services (20), inappropriate dental training towards the changing needs and demands amongst oral health providers (21), behavioural and financial problems (22). Furthermore, oral health awareness and care-seeking behaviour were reported to be low amongst carers but, their children's oral health needs were found to be high (23). Therefore, the care givers including parents, teachers and relatives play an important role in guiding and assisting their children to take care of their oral health. This pilot study was aimed to assess $\mathrm{OHL}$ among selected carers of CSHCN in Kuala Terengganu. The outcome of this study will greatly assist in addressing any lower scores for OHL domains among carers of CSHCN in this population and to develop a more appropriate intervention programmes for carers that match their OHL.

\section{MATERIALS AND METHOD}

This was a descriptive cross-sectional study on $\mathrm{OHL}$ among carers of CSHCN in Kuala Terengganu. There was a total of five special needs centres in Kuala Terengganu; four were day care CommunityBased Rehabilitation Centres and one was a community centre with full boarding for children and adults. Only carers who send their children to the day care Community-Based Rehabilitation Centres in Kuala Terengganu were traced and participants were selected based on the criteria as below:

1. Inclusion criteria: Participant had to be at least 18 years of age and were able to understand and communicate in Malay language.

2. Exclusion criteria: Participant with cognitive impairment, had vision or hearing problem and had obvious sign of drug addiction.

After identifying individuals who had met the inclusion criteria for the research, the individuals were then contacted through the principals of the Community-Based Rehabilitation Centres to set an appointment for the interviews. Consent forms were given to the selected participants and those carers who consented to participate in this study were included. Data collection process at the CommunityBased Rehabilitation Centres was administered over the period of two weeks, from 27 th July to 7 th August 2015.

The OHLI-M was administered to the participants for this study (17). The OHLI-M questionnaires comprised of two sections; reading comprehension and numeracy sections. The reading comprehension section was administered through a guided self-administered questionnaire. The section consisted of two passages; dental caries and periodontal disease. The dental caries passage had 13 incomplete sentences with test items that consisted of 18 omitted words from the sentences. On the other hand, the periodontal disease passage contained 14 sentences with 20 item-words omitted for test items. The respondents were asked to choose one out of four possible choices that were given to complete each sentences. 
In the numeracy section, it consisted of a series of prompts; five prescription labels of medicine frequently prescribed by dentists, one dental appointment card and printed post-extraction instructions. There were 19 test items for this section that were administered through a structured face to face interview. The prompts were shown to the respondents and adequate time was given to the participants to read and understand these prompts. The interviewer will then asked questions related to each prompt starting from the first until the last. The responses were recorded by the interviewer in the scoring sheet.

The test items in both sections were scored one (1) for each correct answer and zero (0) for each incorrect or missing answer. In order to get a weighted score from 0 to 50 for each section, the sum of correct answers was calculated and then multiplied by $1.316(50 / 38)$ for reading comprehension section, whereas the total score of numeracy was multiplied by $2.632(50 / 19)$. The total score for OHLI-M was obtained by summing the total score for the reading comprehension and numeracy sections, which ranges from 0 to 100. The higher the OHLI-M score, the higher the functional OHL. In addition, the total OHLI-M score was categorized into three levels of $\mathrm{OHL}$ namely inadequate (0-59), marginal (60-74) and adequate (75-100).

The data was cleaned and analysed using Statistical Package for the Social Science (SPSS) version 12.0. Descriptive statistics was employed for frequency distribution, means with $95 \%$ confidence interval and level of OHLI-M scores.

This study was approved by the Medical Ethics Committee, Faculty of Dentistry, University of Malaya.

\section{RESULTS}

Of the 108 individuals who were contacted to participate in this study, 40 participants responded; yielding a response rate of $37 \%$. Table 1 shows the distribution of participants by age group, gender, education level and frequency of dental visit. Most of the participants were female $(72.5 \%)$ between 21 and 59 years of age, with a mean age of 39 (SD, 11.13). More than half $(55 \%)$ of them were between $20-40$ years. Majority of the participants had secondary education $(70 \%)$ while the rest had tertiary education. Almost half (45\%) of the participants reported visiting their dental care provider within the last 12 months.
Table 1: Distribution of participants by age group, gender, education level and frequency of dental visit

\begin{tabular}{lll}
\hline & Mean (SD) & $\mathrm{n}(\%)$ \\
All subjects & $40(100)$
\end{tabular}

Age in years

21-40

41-60 $18(45.0 \%)$

Mean age (SD) $\quad 39.63(11.13)$

Gender

Male

Female

Education level

Secondary

Tertiary

Frequency of dental

visit

Within 12 months

1 to 2 years

$6(15 \%)$

Once in pain

$16(40 \%)$
The distribution of OHLI-M scores according to OHLI- M level is shown in Figure 1. Four $(10 \%)$ of the participants were in the 'inadequate' level, fifteen $(37.5 \%)$ belong to the 'marginal' level while more than half $(21$ or $52.5 \%)$ were classified as having 'adequate' OHLI-M level.

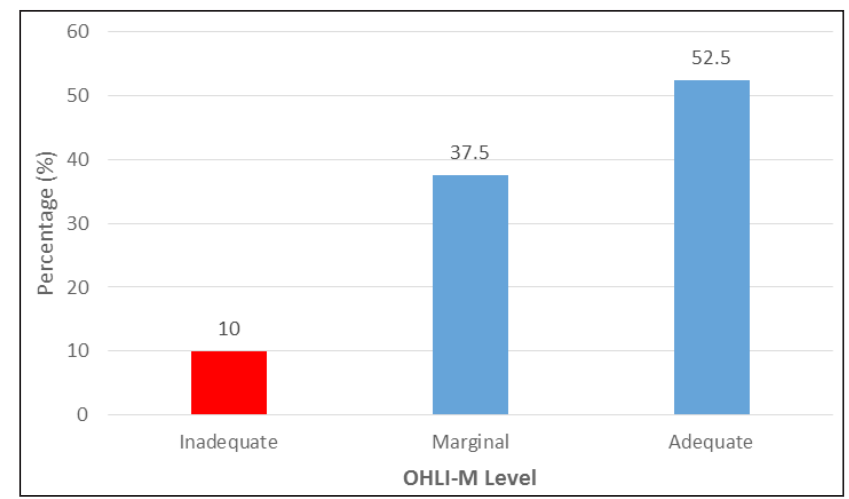

Figure 1: Distribution of OHLI-M scores according to OHLI-M level

Table 2 shows minimum and maximum score for the total OHLI-M and each of its component 
scores. The lowest score for reading comprehension was 25.0 while the highest score was 47.4 . In the numeracy section, the minimum score was 13.2 while the maximum was 50.0. The total OHLI-M scores ranged from 38.2 (minimum) to 97.4 (maximum).

Table 2: Minimum \& maximum score for total OHLI-M, reading comprehension and numeracy sections.

\begin{tabular}{lcc}
\hline & $\begin{array}{c}\text { Minimum } \\
\text { score }\end{array}$ & $\begin{array}{c}\text { Maximum } \\
\text { score }\end{array}$ \\
Reading comprehension & 25.0 & 47.4 \\
Numeracy & 13.2 & 50.0 \\
Total OHLI-M & 38.2 & 97.4 \\
\hline
\end{tabular}

Table 3 shows the distribution of OHLI-M mean scores with $95 \%$ confidence interval. The mean OHLI-M scores for reading comprehension and numeracy sections were $37.54(95 \% \mathrm{Cl} 35.7-39.4)$ and $38.17(\mathrm{Cl} 34.8-41.6)$, respectively. The total OHLI-M mean score was 75.7 (95\% Cl 71.2-80.2) for all participants.

Table 3: Distribution of OHLI-M mean scores (mean and 95\% Confidence Interval)

\begin{tabular}{ll}
\hline & $\begin{array}{l}\text { Mean OHLI-M } \\
\text { Score }(95 \% \mathrm{CI})\end{array}$ \\
$\begin{array}{l}\text { Reading Comprehension } \\
\text { section }\end{array}$ & $37.54(35.7-39.4)$ \\
Numeracy section & $38.17(34.8-41.6)$ \\
Total OHLI-M Score & $75.7(71.2-80.2)$ \\
\hline
\end{tabular}

\section{DISCUSSION}

The CSHCN depend greatly on their carers to take care of their oral hygiene and health practices at home (10-12). Consequently, CSHCN may achieve better oral health outcomes when carers have good knowledge about oral health (24). The OHL measures an individual's ability to perform oral health literacyrelated tasks that require reading comprehension and numeracy skills (16). This instrument is one of the tools to access functional OHL among adult dental patients. The present study was built from the previous work of Ramlay and colleagues who had validated a reliable instrument to measure adults' $\mathrm{OHL}$ in Malaysia (17). Their study was conducted for a general population in a more developed state.
Thus, it was decided for this study to be conducted in a less developed district in Kuala Terengganu, where the socio-demographic status may be different.

Even though this study had included four community-based rehabilitation day care centres, the response rate was relatively poor. This could be due to time constraints as the carers had to take time off from work, or they were not willing to participate as the questionnaires involved answering all the questions in the centres. All participants who consented had secondary and tertiary education. Majority of the carers were from a younger age group and had visited the dentists in the last two years. Therefore, it was recommended that OHLI-M future study should look into the usage of OHLI-M for a wider population, especially those with lower education level and low socio-economic background.

The findings of this study showed that majority $(90 \%)$ of our participants had OHLI-M score of 'marginal' and 'adequate' OHLI-M level. Only four $(10 \%)$ of the participants were in the 'inadequate' level and need to be considered when conducting oral health education and intervention programmes. Comparison with other studies was not possible as this study was highly descriptive and more exploratory in nature. Furthermore, other studies had used different instrument to assess $\mathrm{OHL}$ and also reported the relationship between $\mathrm{OHL}$ and other factors (2-17).

Previous studies had discussed the limitations of the numeracy skills approach to literacy assessment because it did not necessarily indicate that the person understands the meaning of the words (25-26). The higher scores on numeracy section compared to reading comprehension may indicate that the participants were better in extracting information rather than comprehending the information. Most of the participants were able to read correctly and extracted the information given by the dental provider, such as on a dental card appointment and dental procedure post-instructions. As a result, the participants were familiar with the terms and instructions because they had been exposed during previous dental appointments or through mass media advertisement.

The participants in our study were mostly below 40 years of age, and they were able to read and comprehend better than older adults. Perhaps this was one of the reason why this study had a high mean score for total OHLI-M. However, the participants who were above 40 years of age obtained a lower mean score because of their limited 
ability to read the comprehension section. The mean score for numeracy is slightly higher compared to comprehension section because it was conducted through a face to face interview. Therefore, carers can understand the questions better as they were able to ask the interviewer directly. Meanwhile, the comprehension section was self-administered. Hence, the participants can just choose the answer without understanding the meaning of the sentences. Thus, future study could employ face to face interviews to improve the data collected for this study.

\section{CONCLUSIONS}

More than half of the participants scored "adequate" level of OHLI-M indicating that majority of the carers of special needs children for this sample in Kuala Terengganu had moderate OHL. Thus, more appropriate intervention programmes for carers can be developed to match their OHL. However, further studies need to be conducted on a larger and more representative sample of the special needs population.

\section{ACKNOWLEDGEMENTS}

The authors thank Ramlay and colleagues for sharing the Malay version of the $\mathrm{OHL}$ instrument, staff and carers from the Community-Based Rehabilitation Centres in Kuala Terengganu.

\section{REFERENCES}

1. Institute of Medicine. Health Literacy: A Prescription to End Confusion. Washington, DC: National Academies; Press; 2004.

2. Robinson LA, Crabtree MA, Allen NW, Baber G, Boseman JJ, etc all: Health Literacy in Dentistry Action Plan 2010-2015. Chicago, IL: American Dental Association; 2009.

3. Davis TC, Michielutte R, Askov EN, Williams MV,Weiss BD. Practical assessment of adult literacy in health care. Health Educ Behav 1998; 25: 613-24.

4. Berkman ND, Sheridan SL, Donahue KE, Halpern DJ, Crotty K. Low health literacy and health outcomes: an updated systematic review. Ann Intern Med 2011; 19: 97-107.

5. Baker DW, Parker RM, Williams MV, Clark WS, Nurss J. The relationship of patient reading ability to self-reported health and use of health services. Am J Public Health. 1997; 87(6): 1027-30.

6. Parker RM, Baker DW, Williams MV, Nurss JR. The test of functional health literacy in adults: a new instrument for measuring patients' literacy skills. J Gen Intern Med. 1995; 10(10): 537-41.

7. Dewalt DA, Berkman ND, Sheridan S, Lohr KN, Pignone MP. Literacy and health outcomes: a systematic review of the literature. J Gen Intern Med. 2004; 19(12): 1228-39.

8. Parker EJ, Jamieson LM: Associations between indigenous Australian oral health literacy and self-reported oral health outcomes. BMC Oral Health 2010; 10: 3.

9. Guo Y, Logan HL, Dodd VJ, Muller KE, Marks JG, Riley JL 3rd: Health literacy: A pathway to better oral health. Am J Public Health. 2014; 104(7): e85-e91.

10. Divaris K, Lee JY, Baker AD, Vann WF Jr: Caregivers' oral health literacy and their young children's oral health-related quality-of-life. Acta Odontol Scand. 2012; 70(5): 390-397.

11. Miller E, Lee JY, DeWalt DA, Vann WF Jr: Impact of caregiver literacy on children's oral health outcomes. Pediatrics. 2010; 126(1): 107-114.

12. Bridges SM, Parthasarathy DS, Wong HM, Yiu CK, Au TK, McGrath CP: The relationship between caregiver functional oral health literacy and child oral health status. Patient Educ Couns. 2014; 94(3): 411-416.

13. Macek MD, Haynes D, Wells W, Bauer-Leffler S, Cotton PA, Parker RM. Measuring conceptual health knowledge in the context of oral health literacy: Preliminary results. J Public health Dent. 2010; 70(3): 197-204.

14. Jamieson LM, Diwaris K, Parker EJ, Lee JY. Oral health literacy comparisons between Indigenous Australians and American Indians, Community Dent Health. 2013; 30(1): 52-57.

15. Pradhan A, 2012. Exploring Dental behaviours of carers of adults with disabilities: Oral health literacy and psycho-social factors. School of Dentistry, University of Adelaide; Doctor of Clinical Dentistry (Special Need Dentistry) thesis.

16. Sabbahi DA, Lawrence HP, Limeback $H$, Rootman I. Development and evaluation of an oral health literacy instrument for adults. Community Dent Oral Epidemiol 2009; 37: 451-462.

17. Ramlay MZ, Tin Oo MM, Saddki N, Wan Mansor WNA. Validation of Oral Health Literacy Instrument for Malaysian adults. Poster presentation at the National Oral Health 
Conference, Swiss Garden Hotel, Kuala Lumpur, 10-13 November 2014.

18. American Academy of Pediatric Dentistry. Council on Clinical Affairs. Guideline on management of dental patients with special health care needs. Pediatr Dent. 2012; 34(5): 160-165.

19. Australian Bureau of Statistics (ABS) 2004. Disability, Ageing and Carers, Australia: Summary of findings, 2003. Cat No 4430.0. Canberra: ABS.

20. Winitzer RF, Bisgaier J, Grogan C, Rhodes K. "He only takes those type of patients on certain days": Specialty care access for children with special health care needs. Disability and Health Journal. 2012; 5(1): 26-33. doi:10.1016/j. dhjo.2011.10.002.

21. Albino JEN, Inglehart MR, Tedesco LA. Dental education and changing oral health care needs: disparities and demands. Journal of Dental Education. 2012; 76(1):75-88.

22. Lai B, Milano M, Roberts MW, Hooper SR. Unmet Dental Needs and Barriers to Dental Care Among Children with Autism Spectrum Disorders. Journal of Autism and Developmental Disorders. 2011; 42(7): 12941303. doi:10.1007/s10803-011-1362-2.

23. Smith G, Rooney Y, Nunn J. Provision of dental care for special care patients: the view of Irish dentists in the Republic of Ireland. J Irish Dental Assoc 2010; 56: 80-84.

24. Frenkel H, Harvey I, Needs K. Oral health care education and its effecton caregivers'knowledge and attitudes: a randomised controlled trial. Community Dent Oral Epidemiol. 2002; 30(2): 91- 100.

25. Richman JA, Huebner CE, Leggott PJ, Mouradian WE, Mancl LA: Beyond word recognition: understanding pediatric oral health literacy. Pediatr Dent. 2011; 33(5):420-425.

26. Baker DW: The meaning and the measure of health literacy. J Gen Intern Med. 2006; 21(8): 878-883.

\section{Corresponding author:}

\section{Prof. Datin Dr. Rashidah Esa}

Department of Community Oral Health \& Clinical Prevention, Faculty of Dentistry, University of Malaya, 50603, Kuala Lumpur, Malaysia.

Tel: 03-7967 4805

Email: rashidah@um.edu.my 